\title{
Negative Feelings of Gratitude
}

Forthcoming in The Journal of Value Inquiry

\section{Tony Manela}

\begin{abstract}
Philosophers generally agree that gratitude, the called-for response to benevolence, includes positive feelings. In this paper, I argue against this view. The grateful beneficiary will indeed have certain feelings, but in some contexts, those feelings will be profoundly negative. Philosophers overlook this fact because they tend to consider only cases of gratitude in which the benefactor's sacrifice is minimal, and in which the benefactor fares well after performing an act of benevolence. When we consider cases in which a benefactor suffers severely, we see the feelings associated with gratitude can be negative, and even quite painful. I conclude with a discussion of the implications such negative feelings of gratitude have for the normative question of when gratitude is owed, and for the descriptive claim, made by positive psychologists, that gratitude enhances wellbeing.
\end{abstract}

\section{Introduction}

Gratitude is a topic of great disagreement among philosophers. They dispute when it is owed, to whom it can be owed, what it amounts to. One point on which philosophers seem to agree, however, is that gratitude involves feelings, and that these feelings of gratitude are fundamentally positive. My goal in this paper is to argue against this claim. Gratitude does imply certain feelings, but there is no single positive feeling of gratitude, the way there may be a single positive feeling of joy or of pride. Instead, gratitude is (in part) an affective disposition - a disposition to have certain feelings in certain situations. Philosophers have overlooked this fact because they tend to consider cases of gratitude in a narrow context - namely, a context in which the benefactor's sacrifice is minimal, and in which the benefactor generally fares well after performing an act of benevolence. 
When we consider gratitude outside this context, I will show, the feelings associated with gratitude can be negative, and indeed quite painful.

This essay proceeds as follows. In §II, I define "gratitude" and "feeling," and refine the question this essay aims to answer. In $\S$ III and IV, I summarize what philosophers have taken feelings of gratitude to be, and argue against what I call the Consensus View on feelings of gratitude: that feelings of gratitude are invariably positive. In $\S \mathrm{V}$, I identify one normative implication my conclusion has for the question of when

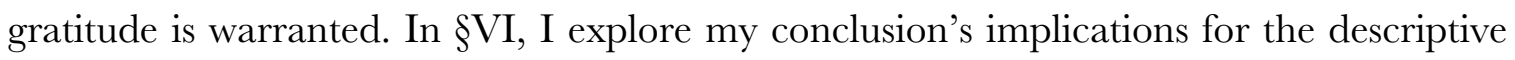
claim, commonly put forward by positive psychologists, that gratitude tends to enhance mental and social wellbeing.

\section{Preliminaries}

Gratitude, as I will understand it in this paper, is the proper or fitting response in a beneficiary to benevolence from a benefactor. This may strike some as an arbitrarily narrow definition of gratitude. As several philosophers have pointed out, ordinary usage of gratitude terms suggests that we can (and sometimes should) be grateful even when there is no benefactor to be grateful to. ${ }^{1}$ It sounds natural to say, for instance, "I am grateful that it did not rain on my wedding day," or "grateful for life's little blessings." As I have argued elsewhere, however, what is expressed in such prepositionless gratitude locutions ultimately amounts to another concept: appreciation. ${ }^{2}$ To be grateful that it did not rain on my wedding day, or for life's little blessings, is simply to appreciate such states of affairs. The concept of gratitude I take as the subject of this paper, by contrast, is a fundamentally interpersonal or inter-agential phenomenon. This stripe of gratitude is 
captured in prepositional gratitude locutions - e.g., gratitude to a stranger for saving one's life, or gratitude to a friend for her support. Gratitude in this sense is the response called for in a beneficiary to something good another agent intentionally does for him. For brevity, I will say gratitude is properly a response to benevolence.

Gratitude, understood as the proper response to benevolence, is a complex phenomenon. It includes, for instance, certain cognitive elements: beliefs about the benefactor (e.g., that she intended to help the beneficiary, that she went above and beyond the call of duty in doing so, etc.), without which a beneficiary might fail to count as grateful. The grateful response also includes certain conative elements. A beneficiary who believes his benefactor has done something gratitude-worthy, but finds no motivation to, say, accede to her reasonable request for help in the future, falls short of gratitude. In addition to certain beliefs and certain motivational tendencies, philosophers agree that gratitude, as the called-for response to benevolence, includes certain affective elements, or feelings. ${ }^{3}$ And this claim seems difficult to deny. A beneficiary who responds to a genuine act of benevolence with mere "cold-blooded thought or desire"4 instead of a certain phenomenological excitement seems to fall short of gratitude in an essential way. It is the feelings called for in response to benevolence - feelings of gratitude - that will be the subject of this paper.

Feelings I will understand as "phenomenally conscious mental episodes." 5 They can range from experiences like itchiness, ticklingness, queasiness and chill ${ }^{6}$ to more global or holistic feelings. When something wonderful happens to me, for instance, I experience feelings of joy; when I do something wonderful, I experience feelings of pride. When something terrible happens to me, or when I am in danger, I experience feelings of sadness or fear, respectively. As these examples suggest, feelings are essential components 
of emotions; indeed, we often label feelings by referring to the emotions they characteristically accompany, and emotions can often be distinguished from one another by the feelings typically associated with them. This is not to say, however, that each emotion is associated with a unique feeling. Feelings of sadness, for instance, may be phenomenologically identical to (and therefore, the same feelings as) feelings of guilt. ${ }^{7}$ What would distinguish the emotions that give rise to such feelings as the emotion of sadness or of guilt would be the causal history, beliefs, or motivational tendencies associated with each instance of a particular feeling. ${ }^{8}$ Regardless of how nuanced the range of possible human feelings turns out to be, I will take it that by and large, feelings can be classified as positive or negative. Positive feelings, like those associated with joy or pride, are pleasant, agreeable, and enjoyable. ${ }^{9}$ Appreciation, the proper response to a beneficial state of affairs, likely includes certain positive feelings like those associated with joy. By contrast, negative feelings, like those associated with itchiness or guilt, are uncomfortable or painful. ${ }^{10}$ With this terminology on the table, I can now state the view against which I will be arguing in the following sections: that the feelings called for in response to a genuine act of benevolence are uniquely or invariably positive.

\section{The Consensus View on Feelings of Gratitude}

The view that feelings of gratitude are positive feelings is widespread among philosophers. ${ }^{11}$ As Peter Costello puts it, "Within one's individual exactment and experience of gratitude, one maintains a certain posture, that of at-homeness, of reflection, of realization and of freedom from anxiety." ${ }^{12}$ Many philosophers hold that a genuine act of benevolence should incite feelings of joy and pleasure in the grateful beneficiary — not just 
because of the benefit, but because he has benefited from someone else's benevolence. ${ }^{13}$ Perhaps a bit more specifically and viscerally, several philosophers have suggested that feelings of gratitude are "warm" feelings. ${ }^{14}$

Some might object to the claim that all philosophers paint such a rosy picture of feelings of gratitude. In particular, Aristotle and Kant are sometimes interpreted as having taken feelings of indebtedness and shame to be appropriate or called-for in the grateful beneficiary, in the sense of being what an ideal beneficiary should feel. ${ }^{15}$ Aristotle, for instance, writes that the megalopsychos "is the sort of person who does good but is ashamed when he receives it; for doing good is proper to the superior person, and receiving it to the inferior." 16 And Kant suggests in the Lectures on Ethics that beneficiaries should cringe at receiving favors, since in doing so, a beneficiary becomes the debtor of his benefactor - a shameful position to occupy. ${ }^{17}$ Closer readings of these philosophers, however, show that they did not believe negative feelings of shame and indebtedness were appropriate for grateful beneficiaries to feel. Taking Aristotle's words in context reveals that negative feelings the megalopsychos experiences in receiving a favor are not part of the proper response to benevolence per se, but response to being in need of benefits from others. ${ }^{18}$ One could imagine a megalopsychos receiving a favor under circumstances that would not shame him (say, a favor he did not need), and under these circumstances, gratitude may be a welcome experience for him. ${ }^{19}$ A closer reading of Kant reveals that in his case too, negative feelings of indebtedness and threatened self-esteem are not feelings a beneficiary necessarily ought to feel; a beneficiary will feel shamed and inferior only insofar as he mistakenly believes his worth as a person is contingent on comparing favorably to others. Ideally, however, a beneficiary will not feel his self-esteem threatened upon receiving a favor, and so will not feel shamed. ${ }^{20}$ Ultimately, then, while 
indebtedness and shame may be natural or common reactions people have when receiving genuine acts of benevolence in certain common circumstances, no philosopher has argued that they are the sorts of feelings beneficiaries should aspire to have in response to another agent's benevolence. They are not thought to be proper, justified or fitting responses to genuine acts of benevolence. I will take it, then, that the claim that feelings of gratitude are positive feelings is widely, if not universally, accepted. Going forward, I will call this claim the Consensus View.

\section{A Critique of the Consensus View}

To see where the Consensus View goes astray, we need to consider how it emerged. Like other generalizations about gratitude, philosophers arrive at the Consensus View by imagining a range of acts of benevolence, and then reflecting on the proper response one would expect to see in an ideally grateful beneficiary under such circumstances. At first glance, the range of such cases considered in the philosophical literature on gratitude seems quite diverse. The types of benefits they consider range from the giving of delightful (but unnecessary) gifts ${ }^{21}$ to the saving of lives. ${ }^{22}$ The beneficiaries in such cases range from total strangers on the verge of death ${ }^{23}$ to friends and family members who request favors of convenience. ${ }^{24}$ The nature and degree of the liability incurred by the benefactor in these cases also seems diverse. At one extreme, the sacrifice of the benefactor takes the form of an inconvenience for the benefactor. Roslyn Weiss and Fred Berger, for instance, consider cases involving the giving of gifts and favors with no specifics or context. ${ }^{25,26}$ In these cases, the benefactor's sacrifice takes the form of the monetary cost of a gift, or the time spent doing a favor for someone. ${ }^{27}$ Other philosophers emphasize the unpleasantness inherent in doing a 
certain favor, such as watching a neighbor's child for a week while she is out of town. ${ }^{28}$ Several analyses consider cases in which the benefactor's sacrifice takes the form of effort expended. A. John Simmons, for instance, imagines a benefactor jumping into a lake and swimming some distance to save a man from drowning. ${ }^{29}$ David Lyons considers a similar case in which the benefactor incurs risk (indeed, grave risk) in addition to expending effort to save a drowning man. ${ }^{30} \mathrm{~A}$ handful of analyses consider cases in which benefactors can be said to suffer in some actual and substantial sense. In one, a benefactor suffers damage to his property, in the form of a broken axel caused by rushing a needy beneficiary to the hospital; 31 in another, a benefactor burns his arm pulling a beneficiary from a burning car. ${ }^{32}$

All these instances of benefactor liability, however, are similar in one critical way: despite the inconvenience, unpleasantness or pain they experience, despite the effort they expend, despite the risk they take, the benefactors in each of these scenarios seem to wind up alright in the end. ${ }^{33}$ Simmons's benefactor has his burn treated, Lyons's benefactor survives his rescue attempt, and the benefactors in the other cases wind up no worse for the wear. To my knowledge, no analysis of gratitude considers a case of benevolence in which the benefactor's sacrifice is dire or extreme - a sacrifice that leaves her horribly off. If the Consensus View is to be warranted about gratitude generally, it must be consistent with such cases. As I will show, however, such cases throw the Consensus View into doubt. Consider a genuine act of benevolence in which the sacrifice of the benefactor is great. Yonas and Robyn ${ }^{34}$ are coworkers in a factory, operating dangerous machinery. One day, Yonas gets both of his hands caught in one of the machines. Robyn is nearby, and realizes that if she does nothing, Yonas will lose both his hands. Thinking quickly (but clearly), she does the one thing she can do to stop Yonas from losing his hands: she sticks 
one of her own hands into the machine, allowing Yonas to withdraw both of his. As a result of this, however, Robyn loses her hand. In such cases, the salient emotion Yonas is likely to feel will not be joy, pleasure, agreeableness, at-homeness, or any positive emotion. Yonas instead should (rightly) feel painful feelings, like those associated with grief, in response to Robyn's sacrifice. This grief might indefinitely overshadow any feelings of appreciation Yonas might have had at retaining his arms, or at having such a caring benefactor. Crucially, however, Yonas need not be ungrateful for his lack of happy feelings here. On the contrary, the absence of negative ones would seem to betray a sort of callous ingratitude. Imagine that after the tragedy, Yonas rejoices in having his arms while blithely ignoring the suffering of his benefactor. "How lucky was I that such a selfsacrificing person happened to be walking by!" he tells his friends afterwards. "I'll never take that luck, or my hands, for granted!" Such a beneficiary may be appropriately appreciative of having two hands (i.e., "grateful" that he has them). He may even be appreciative of the fact that Robyn came to his rescue ("What a great thing that such a self-sacrificing person works right next to me!"’). But if his response to Robyn's act of benevolence does not include negative grief-like feelings, Yonas seems to fall short of being grateful to Robyn. If this is true, then negative feelings are sometimes called for in response to acts of benevolence; and insofar as a grateful beneficiary should sometimes have negative feelings, we can say there are negative feelings of gratitude - painful or aversive feelings that the properly grateful beneficiary ought to have.

The possibility of negative feelings of gratitude helps explain what might otherwise be a puzzling connection, often overlooked among contemporary western philosophers of gratitude: the fact that beneficiaries sometimes have simultaneous urges to thank and apologize to a benefactor in response to one and the same act of benevolence. Imagine 
Yves is leaving a supermarket with two armfuls of groceries when he stumbles and falls, spilling his groceries across the parking lot. Remy, a benevolent stranger with a single armful of groceries, bends over to help him, and in the process, spills her own groceries all over the parking lot. Most people in Yves' situation would feel the urge not only to thank the stranger for stopping, but to apologize, or at least express regret, for the sacrifice she made in stopping to help. That the proper response to a benefactor's act of benevolence is mixed up with feelings of regret for the sacrifices they make in performing them is more obvious in certain linguistic traditions than in others. In Japanese, for instance, a common word for expressing gratitude, sumimasen, also commonly serves as a remedial expression ("excuse me," or "I'm so sorry"), depending on the context. Devoid of context, though, sumimasen expresses a mix of gratitude (for an act of benevolence) and apology (for being the causal centerpiece of the benefactor's sacrifice or inconvenience in performing it). The word thus nicely captures an important (though overlooked) way in which gratitude can be a painful experience for the grateful beneficiary.

It might be objected that the negative feelings Yves experiences (or should, it seems, experience) in this case, while natural, are ultimately irrational, unjustified or inappropriate feelings. ${ }^{35}$ After all, Yves did nothing wrong; he did not wrong Remy, nor was he morally responsible for the harm that befell her, and so neither apology nor genuine contrition is called for. Indeed, Remy would be quite likely to refuse Yves's apology, on the grounds that he had nothing to apologize for. Any contrition or regret Yves might feel would thus be inappropriate or unjustified, like so-called "agent-regret": the regret of a morally innocent agent whose decisions or choices lead to a tragedy. Yves, of course, was not so much the agent as the patient in this case, so perhaps the term "patient-regret" is more appropriate here. 
It may be true that contrition or apology is in such instances an irrational (if natural) emotion; but that does not mean the regret and the associated negative feelings that Yves feels are inappropriate. Regret or grief for the suffering of the benefactor still seems called for - that is, rational and justified, and not merely natural. Consider the following twist on the supermarket parking lot case: when Remy stops to help Yves pick up his groceries, she does not spill her own, and succeeds in getting Yves up, repacked, and back to his car in a few moments, without suffering any terrible sacrifice in the process. Yves makes it home safely. The next day, however, he reads in the newspaper that Remy was killed the night before. She had returned home from the grocery store and walked in on a burglary in progress. The details from the police report make it clear that the few moments Remy spent helping Yves the day before would not have changed the fact that she would have walked in on the burglary if she had not helped, so Yves need not feel patient-regret; nor could the tragedy be construed as a sacrifice Remy made for Yves. Still, though, insofar as Yves is grateful to Remy, we would expect him to be especially saddened, aggrieved or outraged when he hears the news of Remy's death. In particular, we would expect him to be more upset than he would be if he read of a similar tragedy befalling a total stranger. At the very least, if he remained totally unmoved upon reading about Remy, we would think him not only coldhearted, but ungrateful. What this shows is that when a benefactor suffers, a grateful beneficiary should experience negative feelings, like those of grief. This is especially true when a benefactor suffers in aiding a beneficiary; but it is also true whenever a benefactor suffers in the future.

Taken together with paradigm cases of gratitude that led to the Consensus View, my cases of Yonas and Yves suggest the following generalization about feelings of gratitude: as far as feelings go, the grateful beneficiary will have certain positive feelings, 
like those of joy or pleasure, so long as his benefactor fares well; and certain negative feelings, like those of grief or anger, when his benefactor fares poorly. We can think of this conjunction of tendencies as goodwill. ${ }^{36}$ Goodwill in this sense should be understood not strictly speaking as a feeling, but as a disposition to have certain feelings in certain situationswhat we might call an affective disposition. For a beneficiary to be grateful to his benefactor is (in part) for the beneficiary to have heightened dispositions to be pleased if things go well for her, and displeased or upset if things go poorly for her. Feelings of gratitude, then, are not uniquely positive; sometimes negative feelings, like those of grief, sorrow or anger, are what make a beneficiary grateful.

\section{A Normative Implication}

In what remains of this paper, I want to explore several implications my conclusion has for other debates about gratitude. The first is an implication for a normative question about gratitude - specifically, about when gratitude is actually warranted. One particular point of disagreement on this question is whether a beneficiary must want, or be content with, the fact that some particular benefactor conferred some particular benefit, in order for gratitude to be warranted. Simmons, for example, writes that if the beneficiary did not want a particular benefit to be provided by some particular benefactor, then the beneficiary owes no debt of gratitude to the benefactor. ${ }^{37}$ Simmons is motivated by reasonable concerns about what a beneficiary might owe to a clumsy or controlling or generally unliked benefactor. It seems plausible to say that an egalitarian need not be grateful for special treatment he receives, ${ }^{38}$ or that a man need not be grateful to his officious and intrusive neighbor for mowing his lawn, unasked. ${ }^{39}$ But cases of great 
benefactor sacrifice seem to pose a counterexample to the claim that a beneficiary must be happy, or want a benefactor to have benefited him the way she did, in order for gratitude to be in order. Imagine a modified version of the case of Robyn and Yonas, where Yonas gets both his hands stuck in the machine, and Robyn must sacrifice both of her hands to save Yonas's, which Robyn does. It seems plausible to think that Yonas might grieve so deeply for Robyn's suffering that all things considered, he is unhappy at having been benefited by her at that moment in that way. He would have preferred a state of affairs in which he lost his hands and she kept hers. Like Yonas, many beneficiaries who are sufficiently sensitive to the suffering of those around them might be inclined not to want others to sacrifice on their behalf. Still, though, it would seem absurd to say such beneficiaries do not owe their benefactors gratitude for their sacrifices. The fact that there can be negative feelings of gratitude highlights the possibility that beneficiaries may be quite unhappy receiving acts of benevolence from certain benefactors who still deserve a great deal of gratitude. If philosophers are concerned to rule out the appropriateness of gratitude in cases like Simmons's, they need to be more fine-grained about a beneficiary's reasons for not wanting a particular benefit to have been conferred by a particular benefactor.

VI. Descriptive Implications and Positive Psychology

Normative questions aside, the possibility of negative feelings of gratitude also has implications for descriptive claims about gratitude. In particular, it casts doubt on two claims made by philosophers and positive psychologists who hold that gratitude essentially enhances psychological and social wellbeing. ${ }^{40}$ The first is the claim that 
gratitude, when present in a beneficiary, serves as an antidote to certain negative (painful or aversive) attitudes. ${ }^{41}$ Consider, for instance, the negative attitude of regret: an attitude in which "some action, event, or state of affairs is construed as unfortunate and contrasted with some more propitious alternative." Regret, I take it, is a negative attitude, which contributes to (and perhaps partly constitutes) unhappiness. Some philosophers believe that gratitude can protect against or mitigate such painful attitudes. As Robert Roberts puts it, the grateful beneficiary "has a shield against such debilitating regrets because he or she is inclined to dwell on the favorable, rather than the regrettable." ${ }^{42}$ This may be perfectly true of a dispositionally appreciative person - someone who habitually seeks out the silver lining in all things that come his way. But it is not necessarily true that a grateful beneficiary will be inclined to dwell on the favorable and not the regrettable. That will only be true in cases in which the benefactor fares well. As my examples in section §IV showed, this is not always the case. A properly grateful beneficiary in Yves's or Yonas's shoes might (and perhaps should) be inclined to dwell on the regrettable fact that his benefactor suffered, especially if the benefactor suffered in performing her genuine act of benevolence.

Consider now the attitude of resentment. Resentment is often held to be a negative emotion, evoking unpleasant and aversive feelings in the resenter. ${ }^{43}$ Gratitude, however, is believed to mitigate resentment. ${ }^{44}$ In receiving a favor or a kindness from someone who has harmed or wronged me in the past, the goodwill I experience toward my benefactor may indeed go a long way toward neutralizing the ill will I bore her previously. Even if gratitude does tend to mitigate resentment toward the benefactor, however, it may still serve as the basis for heightened resentment toward third parties. Imagine that in the parking lot case, Yves had never spilled his groceries, and Remy had 
never stopped to help him. When Yves reads about Remy's murder in the newspaper the next morning, he may be saddened, and perhaps angry at the murderers; but in the case where Remy helped Yves just before returning home to her untimely demise, it seems plausible that Yves would experience a great deal more resentment toward Remy's assailants than he would have otherwise. He might find himself more likely, in the following weeks, to lose sleep and be distracted by his angry feelings than if he lacked the proper grateful affective disposition, or if Remy had never helped him in the first place. Gratitude, then, may in fact lead a grateful beneficiary to experience more resentment than if he had never received some act of benevolence. And insofar as resentment and regret are associated with negative feelings, gratitude may sometimes heighten, rather than ameliorate, such feelings in a grateful beneficiary. ${ }^{45}$

Consider now the claim that gratitude, as the proper response to benevolence, is socially constructive. This claim follows from the Consensus View of feelings of gratitude as positive feelings, together with the (plausible) assumption that such feelings can motivate certain pro-social behavior. On the basis of those premises, it could be argued that gratitude tends to build beneficial interpersonal relationships, like friendships. ${ }^{46}$ When a beneficiary is grateful, he is inclined to benefit his benefactor and bear her goodwill. She, in turn, will be inclined to bear him even more goodwill, and be even more motivated to benefit him in the future. As the cycle continues, the social bond between beneficiary and benefactor grows. ${ }^{47}$ This might lead us to believe that the more grateful the people in a society, the more friendship and camaraderie we would expect to see within it. But this generalization may be too hasty. Gratitude may indeed be socially constructive insofar as we consider the beneficiary's relationship with the benefactor. When we consider the beneficiary's relationship to third parties, however, things might be 
radically otherwise. Recall that in the case of Remy and Yves, it seemed plausible that Yves's gratitude to Remy would result in heightened feelings of anger toward the people who murdered Remy. Insofar as such feelings motivate anti-social behavior, and impair relationships between individuals, it would also seem to follow that Yves's gratitude to Remy would result in impaired relationships with the people who harmed her. This might manifest itself in a heightened reluctance on Yves' part to forgive the perpetrators, or to welcome them back into society after they serve prison sentences and atone for their evil deed. This reluctance need not be undue; indeed, in a society where people tend to forgive too easily, the reluctance to forgive that might result from gratitude to a victim could be perfectly reasonable, and quite healthy for society overall. The fact would still remain, however, that gratitude can have a detrimental effect on the formation and repair of social relationships - a point that becomes clear only when we admit the possibility of negative feelings of gratitude.

If what I have said is correct, the possibility of negative feelings of gratitude gives us reason to qualify the claim that gratitude contributes to mental and social wellbeing. ${ }^{48}$ The strongest claim consistent with my conclusions that positive psychologists can make is that gratitude is psychologically and socially beneficial so long as the benefactor fares well. The general consensus that gratitude contributes to mental and social wellness might be reliably true and applicable in affluent, peaceful societies, where everyone, including benefactors, is likely to fare well; but things may be quite different in contexts where poverty, disease, injustice and violence are widespread. Under such circumstances, where the benevolent and kindhearted are likely to suffer, a grateful beneficiary might very well grieve and hate more often and more deeply than an ungrateful one. 


\section{Conclusion}

In this paper, I have argued that feelings of gratitude are not uniquely positive. Feelings of appreciation may be; and feelings of gratitude when a benefactor fares well may be also. But gratitude is often called for in cases where a benefactor suffers dearly, and any accurate generalizations about gratitude must take such cases into account. When we do consider such cases, we see that feelings of gratitude can sometimes be negative, can sometimes promote (rather than ameliorate) other negative feelings, and can sometimes be detrimental to social relationships. Negative feelings of gratitude also illuminate the possibility that gratitude might be called for even when the beneficiary of an act of benevolence would have preferred not to be benefited in some particular way by some particular benefactor. As philosophers and psychologists continue to research the normative and descriptive dimensions of the proper response to benevolence, they should keep these points in mind, and should treat seriously cases of gratitude where a benefactor sacrifices dearly or suffers terribly.

Notes

\footnotetext{
${ }^{1}$ See, for instance, A. D. M. Walker, "Gratefulness and Gratitude," Proceedings of the Aristotelian Society 81 (1980-1981); Claudia Card, "Gratitude and Obligation," American Philosophical Quarterly 25, no. 2 (1988); Sean McAleer, "Propositional Gratitude," ibid.49, no. 1 (2012).
} 
${ }^{2}$ Tony Manela, "Gratitude and Appreciation," forthcoming in American Philosophical Quarterly. See also Liz Gulliford, Blaire Morgan, and Kristján Kristjánsson, "Recent Work on the Concept of Gratitude in Philosophy and Psychology," Journal of Value Inquiry 47 (2013).

${ }^{3}$ See, for instance, Patrick Fitzgerald, "Gratitude and Justice," Ethics 109, no. 1 (1998): 120; Roslyn Weiss, "The Moral and Social Dimensions of Gratitude," The Journal of Southern Philosophy XXIII, no. 4 (1985): 493; Joel Feinberg, "Duties, Rights, and Claims," American Philosophical Quarterly 3, no. 2 (1966): 139.

${ }^{4}$ Michael Stocker, "Psychic Feelings: Their Importance and Irreducibility," Australasian Fournal of Philosophy 61, no. 1 (1983): 8-9.

${ }_{5}^{5}$ Jesse Prinz, "Are Emotions Feelings?," Journal of Consciousness Studies 12, no. 8-10: 9.

${ }^{6}$ These examples come from Laura Sizer, "What Feelings Can't Do," Mind \& Language 20, no. 1 (2006): 110.

7 Prinz, "Are Emotions Feelings?," 19.

${ }^{8}$ Ibid.

${ }^{9}$ Gulliford, Morgan, and Kristjánsson, "Recent Work on the Concept of Gratitude in Philosophy and Psychology," 307.

${ }^{10}$ Robert C. Roberts, "The Blessings of Gratitude," in The Psychology of Gratitude, ed. Robert A. Emmons and Michael E. McCullough (Oxford: Oxford University Press, 2004), 64.

${ }^{11}$ It is put forward explicitly by, inter alia, Gulliford, Morgan, and Kristjánsson, "Recent Work on the Concept of Gratitude in Philosophy and Psychology," 307; Samuel Bruton, "Duties of Gratitude," Philosophy in the Contemporary World 10, no. 1 (2003): 3; James Ceaser, "On Gratitude," in Endangered Virtues Essays, ed. Peter Berkowitz (2011), 2; Fitzgerald, "Gratitude and Justice," 120.

${ }_{12}$ Peter R. Costello, "Towards a Phenomenology of Gratitude: What Is 'Pleasing' in the Euthyphro," Proceedings of the American Catholic Philosophical Association 79 (2006): 262.

${ }^{13}$ Lucius Annaeus Seneca, On Benefits, trans. Miriam Griffin and Brad Inwood (Chicago: University of Chicago Press, 2010), III.3.3; Paul F. Camenisch, "Gift and Gratitude in Ethics," The Fournal of Religious Ethics 9, no. 1 (1981): 8, 18; Card, "Gratitude and Obligation," 124; Terrance McConnell, Gratitude (Philadelphia, PA: Temple University Press, 1993), 83.

${ }^{14}$ Fitzgerald, "Gratitude and Justice," 120; Card, "Gratitude and Obligation," 119.

15 "Gratitude and Obligation." 
16 Aristotle, "Nicomachean Ethics," in The Complete Works of Aristotle, ed. Jonathan Barnes (Princeton: Princeton University Press, 1995), 1124b10-14.

17 Immanuel Kant, Lectures on Ethics, trans. Louis Infield (Cambridge: Hackett, 1979), 118-19.

18 Kristján Kristjánsson, "An Aristotelian Virtue of Gratitude," Topoi (2013).

${ }^{19}$ Indeed, as Kristjánsson points out, Aristotle's discussion of kharis in the Rhetoric seems to indicate that he thought the experience of gratitude could be positive. See ibid., §3.

${ }^{20}$ Houston Smit and Mark Timmons, "The Moral Significance of Gratitude in Kant's Ethics," The Southern Journal of Philosophy 49, no. 4 (2011): 310.

${ }^{21}$ Christopher Heath Wellman, "Gratitude as a Virtue," Pacific Philosophical Quarterly 80 (1999).

22 Daniel Lyons, "The Odd Debt of Gratitude," Analysis 29, no. 3 (1969).

23 Ibid.

${ }^{24}$ Bruton, "Duties of Gratitude."

25 Weiss, "The Moral and Social Dimensions of Gratitude."

${ }^{26}$ Fred Berger, "Gratitude," Ethics 85, no. 4 (1975): 299.

27 McConnell, Gratitude, 18; Bruton, "Duties of Gratitude," 2.

28 "Duties of Gratitude," 2.

${ }^{29}$ A. John Simmons, Moral Principles and Political Obligations (Princeton, NJ: Princeton University Press, 1979), 170 ; ibid.

30 Lyons, "The Odd Debt of Gratitude," 94.

${ }^{31}$ Simmons, Moral Principles and Political Obligations, 171.

32 Ibid.

33 Or so the context in each case seems to imply.

${ }^{34}$ For the sake of clarity, I will use names beginning with the letter $\mathrm{Y}$ to refer to a beneficiary, and names beginning with the letter $\mathrm{R}$ to refer to a benefactor. I will also use masculine pronouns to refer to beneficiaries, and feminine pronouns to refer to benefactors.

${ }^{35}$ For more on this distinction, see Justin D'Arms and Daniel Jacobson, "The Moralistic Fallacy: On the 'Appropriateness' of Emotions," Philosophy and Phenomenological Research 61, no. 1 (2000). 
${ }^{36}$ In using this term, I follow Walker, "Gratefulness and Gratitude." Importantly, though, Walker uses the term to refer only to the first conjunct - a tendency to be pleased when a benefactor fares well. Walker never mentions the tendency to be displeased or upset when things go poorly for a benefactor.

${ }^{37}$ Simmons, Moral Principles and Political Obligations, 178; Walker, "Gratefulness and Gratitude," 49, could be construed as making a similar point.

38 This example comes from "Gratefulness and Gratitude."

39 This is a modified version of an example from Simmons, Moral Principles and Political Obligations.

${ }^{40}$ For a summary of recent psychological literature making this claim, see Gulliford, Morgan, and Kristjánsson, "Recent Work on the Concept of Gratitude in Philosophy and Psychology," and P. C. Watkins, Gratitude and the Good Life: Toward a Psychology of Appreciation (Springer, 2013), chapters 4, 8 and 10. My goal in this section is to give non-empirical reason for doubting this claim, rather than criticizing the data and empirical methods that psychologists have taken to support it (though I will briefly address empirical research on the positive psychological effects of gratitude in note 48, below).

${ }^{41}$ Roberts, "The Blessings of Gratitude," 66.

${ }^{42}$ Ibid., 70.

${ }^{43}$ See, for instance, Roberts, "The Blessings of Gratitude," 67.

${ }^{44}$ Ibid.

45 The fact that gratitude might sometimes take the form of negative feelings suggests that a similar claim might hold, mutatis mutandis, for certain paradigmatically negative attitudes, like anger. Consider, for instance, the widely held claim that feelings of anger are negative feelings. This may be true for a certain kind of anger - anger that something (bad) has transpired. But when it comes to being angry at someone for doing something, the feelings associated with anger need not always be unpleasant. Imagine I am driving the speed limit in the right lane on a highway, when another car speeds up behind me suddenly, and begins to tailgate me and sound his horn aggressively. I have my two children in the car, so I fear for their safety, and resent the tailgater for his reckless behavior. After a minute or two, he whips into the left lane, and sends me an offensive gesture as he speeds past, disappearing into the distance. Five minutes later, I round a bend in the road to see him pulled over on the shoulder in front of a police cruiser, getting ticketed. In that 
moment, I feel good - and not simply because I know that the roads are that much safer. I feel good, and I might very well feel better than another driver who, say, saw all these events transpire from a safe distance. 46 See, for instance, Roberts, "The Blessings of Gratitude," 68.

47 Ibid., 67.

48 At this point, one might worry that the reasons I have given in the previous paragraphs are contradicted, and ultimately outweighed, by the copious research from experimental psychologists suggesting that gratitude does in fact lead consistently to social and psychological wellbeing (see note 40 , above). In the face of such empirical research, the worry goes, my arguments in this section are rendered unpersuasive.

Though a full reply to such a worry would require a paper of its own, several brief remarks will, I hope, suffice for the moment. The first is that many experimental studies on gratitude may not actually contradict my claim that gratitude sometimes enhances mental disturbance and social strife, since most psychologists do not distinguish between gratitude and appreciation the way I did in §II (see Gulliford, Moran, and Kristjánsson, "Recent Work on the Concept of Gratitude in Philosophy and Psychology"). Their data may suggest that an amalgam of gratitude and appreciation always promotes mental and social wellbeing, but they may not tell us very much about gratitude, the proper response to benevolence, in and of itself.

Even if experimental psychologists did distinguish between gratitude and appreciation, however, some of them might still take their data to endorse the claim that gratitude, as the called-for response to benevolence, is uniformly conducive to wellbeing in the ways I have described in this section. Insofar as they do, such psychologists may be guilty of a mistake similar to that of philosophers I discussed in $\S I V$ : i.e., failing to test the connection between gratitude and wellbeing across cases in which the benefactor suffers terribly. My suspicion is that when gratitude is considered in isolation, and psychologists collect data on subjects' responses to benevolence in scenarios where a benefactor suffers substantially, they may well find empirical support for the claims I have made in this section. 